\title{
Gallstones and the risk of biliary tract cancer: a population-based study in China
}

\author{
AW Hsing ${ }^{*, 1}$, Y-T Gao ${ }^{2}$, T-Q Han ${ }^{3}$, A Rashid ${ }^{4}$, LC Sakoda ${ }^{5}$, B-S Wang ${ }^{6}$, M-C Shen ${ }^{7}$, B-H Zhang ${ }^{8}$, S Niwa9 \\ $J^{\prime} C^{10}$ and JF Fraumeni Jr'
}

'Division of Cancer Epidemiology and Genetics, National Cancer Institute, Bethesda, MD, 20852-7234, USA; 2Shanghai Cancer Institute, Shanghai, China; ${ }^{3}$ Ruijin Hospital, Shanghai Second Medical University, Shanghai, China; ${ }^{4}$ Department of Pathology, University of Texas MD Anderson Cancer Center, Houston, TX 77030, USA; ${ }^{5}$ Department of Epidemiology, University of Washington, Seattle, WA 98195; ' ${ }^{6}$ hongshan Hospital, Fudan University, Shanghai, China; ${ }^{7}$ Shanghai Tumor Hospital, Shanghai, China; ${ }^{8}$ Institute of Oriental Hepatobiliary Surgery, Second Military Medical University, Shanghai, China; ${ }^{9}$ Westat Inc., Rockville, MD, USA; ${ }^{10}$ University of Pennsylvania, Philadelphia, PA, USA

\begin{abstract}
We conducted a population-based study of 627 patients with biliary tract cancers (368 of gallbladder, 191 bile duct, and 68 ampulla of Vater), 1037 with biliary stones, and 959 healthy controls randomly selected from the Shanghai population, all personally interviewed. Gallstone status was based on information from self-reports, imaging procedures, surgical notes, and medical records. Among controls, a transabdominal ultrasound was performed to detect asymptomatic gallstones. Gallstones removed from cancer cases and gallstone patients were classified by size, weight, colour, pattern, and content of cholesterol, bilirubin, and bile acids. Of the cancer patients, $69 \%$ had gallstones compared with $23 \%$ of the population controls. Compared with subjects without gallstones, odds ratios associated with gallstones were 23.8 (95\% confidence interval (Cl), 17.0-33.4), 8.0 (95\% Cl 5.6- | I.4), and 4.2 (95\% Cl 2.57.0) for cancers of the gallbladder, extrahepatic bile ducts, and ampulla of Vater, respectively, persisting when restricted to those with gallstones at least 10 years prior to cancer. Biliary cancer risks were higher among subjects with both gallstones and self-reported cholecystitis, particularly for gallbladder cancer $(\mathrm{OR}=34.3,95 \% \mathrm{Cl}$ 19.9-59.2). Subjects with bile duct cancer were more likely to have pigment stones, and with gallbladder cancer to have cholesterol stones $(P<0.00 \mathrm{I})$. Gallstone weight in gallbladder cancer was significantly higher than in gallstone patients (4.9 vs 2.8 grams; $P=0.00$ I). We estimate that in Shanghai $80 \%$ (95\% Cl 75-84\%), 59\% (56-61\%), and 41\% (29-59\%) of gallbladder, bile duct, and ampulla of Vater cancers, respectively, could be attributed to gallstones. British Journal of Cancer (2007) 97, I577- I582. doi: I0.I038/sj.bjc.6604047 www.bjcancer.com
\end{abstract}

Published online 13 November 2007

(c) 2007 Cancer Research UK

Keywords: biliary tract cancer; gallstones; cholecystitis; China

Cancers of the biliary tract encompass those arising from the gallbladder, extrahepatic bile ducts, and ampulla of Vater. Biliary cancer is relatively uncommon in most parts of the world, although high-risk populations and upward incidence trends have been reported in certain areas (Hsing et al, 1998, 2006). Although gallstones are a well-documented risk factor for gallbladder cancer (Diehl, 1983, 1991; Zatonski et al, 1997; Lazcano-Ponce et al, 2001; Hsing et al, 2006), their role in cancers of the extrahepatic bile duct and ampulla of Vater is less established.

From 1972 to 1994, biliary tract cancer was the most rapidly rising malignancy in Shanghai (Hsing et al, 1998), involving all three subsites, both sexes, and all age groups. We therefore conducted a population-based case - control study there in 1997 to 2001 to assess the role of gallstones for each biliary cancer subsite.

* Correspondence: Dr AW Hsing, Division of Cancer Epidemiology and Genetics, National Cancer Institute, EPS 5024, MSC 7234, 6120 Executive Blvd., Bethesda, MD 20852-7234, USA;

E-mail: hsinga@mail.nih.gov

Received 10 September 2007; revised 26 September 2007; accepted 26 September 2007; published online 13 November 2007

\section{MATERIALS AND METHODS}

\section{Cancer cases}

The study was approved by the Institutional Review Boards at both the National Cancer Institute and the Shanghai Cancer Institute. Informed consent was obtained for all subjects. Patients with primary biliary tract cancer (ICD9 156), newly diagnosed between June 1997 and May 2001, were identified through a rapid-reporting system established between the Shanghai Cancer Institute and 42 collaborating hospitals in 10 urban districts of Shanghai (henceforth referred to as urban Shanghai), which captured over 95\% of relevant cases. Cancer cases were permanent residents of urban Shanghai without a previous non-skin cancer. A total of 627 biliary cancers were enrolled, representing over $90 \%$ of the eligible cases.

\section{Pathology and clinical review}

The cancer site was determined from the surgical/pathology report of the local hospital and confirmed by reviewing radiologic data, including magnetic resonance imaging, ultrasonography, computer tomography, and endoscopic retrograde cholangiopancreatography and histopathology. Because biliary cancer is usually 
diagnosed at a fairly late stage, many tumours were unresectable, and only $458(68.8 \%)$ cases had histological specimens available for review. Confirmation was both clinical and through independent slide review by local pathologists and also by a panel of five leading Shanghai pathologists and one from the US (AR). A consensus review was carried out to resolve any discrepancy. Over $74 \%$ of gallbladder and $57 \%$ of bile duct cancer cases were confirmed by histology. Whenever possible, staging was evaluated based on the tumour-node-metastasis system of the American Joint Committee on Cancer.

For a total of $185(29 \%)$ cases without pathological tissue, mostly due to unresectable tumours, imaging data as well as clinical and operative reports were referred to the clinical review panel (four leading gastrointestinal surgeons and a pathologist). A total of nine cases with neither tissue nor clinical data for confirmation were excluded from the study.

\section{Gallstone cases}

A total of 1037 patients with biliary stones undergoing cholecystectomy or medical treatment at the same hospital as the index case were selected and matched by gender and age (within 7 years) (1) to assess risk factors specific to cancer and (2) to collect such samples as gallstones, bile, and snap-frozen tissue for biochemical and molecular analyses. Over $95 \%$ of eligible stone cases participated. Similar clinical and histopathological assessments of the biliary tract were carried out for all cases with stones.

\section{Population controls}

A total of 959 healthy subjects, without a history of cancer, were randomly selected from the 6.5 million permanent residents of Shanghai as population controls, using the personal registry cards of all adults over age 18 in urban Shanghai. They were frequencymatched to the expected age distribution (5-year category) of the cancer cases. Controls with a history of non-skin cancer were ineligible: over $83 \%$ of eligible controls participated.

\section{Interviews}

In-person interviews were conducted with all study subjects, using a structured questionnaire, by trained interviewers on potential risk factors, including smoking, alcohol, body size, diet, reproductive history, family history of cancer, medical history, and physical activity. Detailed information was obtained on biliary diseases, including a history of gallstones, date of diagnosis and treatment, inflammatory conditions, and surgical procedures. Each interview was taped, reviewed, and verified by a supervisor. In addition, $5 \%$ of the controls were randomly selected for a second interview within 3 months after the original interview to assess reproducibility. Concordance between the two interviews was over $95 \%$.

\section{Gallstone status}

Great care was taken to ensure the validity of the classification of gallstone status among study subjects. For cancer cases, in addition to self-reports of a gallstone history, operative reports and imaging data were used; details of gallstone location at cancer diagnosis were collected. Similar procedures were used to confirm gallstone status in the 1037 gallstone patients. For controls, in addition to a self-reported gallstone history, transabdominal ultrasound was performed to validate gallstone status and to identify silent gallstones. Evidence of biliary sludge based on ultrasound examination was also recorded, although sludge alone was not classified as gallstones. One hundred and twenty (13\%) controls did not participate in ultrasound examination; their gallstone status was determined solely by self-reports.
Biological samples, including overnight fasting blood, gallstones, and tissue, were collected from study subjects whenever possible. Information on number, size, colour, and type of gallstones was obtained from surgical and pathology reports and medical records, when available; weight was based on the collected stones. Gallstones were successfully collected from 51 cancer patients and 520 gallstone patients for morphological and biochemical classification. Based on the surface and cross-section of the largest stone, six colour categories were formed: white, light yellow, dark yellow, light brown, dark brown, and black.

\section{Chemical classification of gallstones}

The largest stone was washed by saline and then ground into powder and analysed for cholesterol, bilirubin, and total and specific bile acids, such as cholic, chenodeoxycholic, deoxycholic, glycocholic, glychenodeoxycholic, and glycodeoxycholic acids (Oda et al, 1975; Roda et al, 1975; Fossati et al, 1989; Wang et al, 1990). The cholesterol and bile acid content was measured by high-performance liquid chromatography, while bilirubin concentration was measured by enzymatic methods (Roda et al, 1975; Han et al, 1998). The collected gallstones were dissolved by adding $10 \mathrm{mg}$ of dry gallstone powder in $10 \mathrm{ml}$ dimethylsulphoxide, and were vortexed rigorously for complete dissolving. After addition of sodium tartrate, the OD value at $600 \mathrm{~nm}$ was measured on the Beckman ultraviolet spectrophotometer. Cholesterol concentration was estimated as: bilirubin ( $\mathrm{mg}$ per $100 \mathrm{mg})=10 \times$ OD (Sample)/ OD (standard reference). Cholesterol stones were defined as stones whose cholesterol content exceeded $50 \%$.

\section{Statistical analysis}

Unconditional logistic regression was used to compute odds ratios (ORs) and 95\% confidence intervals (CIs) for each cancer subsite associated with gallstones (yes/no) separately, adjusting for age $(<55,55-64, \geqslant 65)$, sex, and educational level (none or primary, junior middle, senior middle, or some college). Gallbladder cancer patients were compared with population controls with an intact gallbladder (without cholecystectomy), while patients with bile duct or ampullary cancer were compared with control subjects, since cholecystectomy does not involve the bile duct or ampulla of Vater. Sex-specific analyses were performed, since gallstones and gallbladder cancer are more common in women. Covariates, including cigarette smoking, alcohol use, education, and history of diabetes or hypertension, were evaluated as potential confounding variables but excluded from the final regression models since they did not appreciably change the risk estimates. Joint effects on biliary cancers of gallstones and several of their risk factors, including diabetes, body mass index (BMI, weight $(\mathrm{kg}) /$ height $\left.(\mathrm{m})^{2}\right)$, chronic cholecystitis, and pancreatitis, were examined by stratified analysis. A cross-product term was included in the regression model to evaluate the significance of interactive effects. All tests were two-sided, with $P<0.05$ defined as statistically significant. Attributable risk was calculated using the Epitome program, using the standard formula $\mathrm{PAR}=\mathrm{Pe}(\mathrm{RR}-1)$ / $(1+\mathrm{Pe}(\mathrm{RR}-1)$, where $\mathrm{Pe}$ is the prevalence of gallstones among controls and ORs the estimate of relative risk (RR) (Rothman and Greenland, 1998).

\section{RESULTS}

A total of 627 biliary cancer patients (368 gallbladder, 191 bile duct, and 68 ampulla of Vater), 1037 stone patients (774 gallbladder and 263 bile duct), and 959 healthy controls were included. Most cancers were diagnosed at an advanced stage: 70 , 61 , and 44 of gallbladder, bile duct, and ampulla of Vater cancers, respectively, were diagnosed at stage III or IV. Of the tumours with 
histopathological information, over $90 \%$ were adenocarcinomas. Cancers diagnosed incidentally during surgery for gallstones accounted for $26.1,14.1$, and $8.8 \%$ of the patients with gallbladder, bile duct, and ampulla of Vater cancers, respectively. Of the 191 extrahepatic bile duct cancers, over half (60\%) were in the upper third (including the cystic duct), $6 \%$ in the middle third, $10 \%$ in bile duct not otherwise specified, $18 \%$ in the lower third, and $6 \%$ in other or multiple parts. Among gallstone patients, $8.1 \%$ had intestinal metaplasia while $5.3 \%$ had dysplasia/carcinoma in situ.

Table 1 shows selected characteristics of cases and controls with age (due to matching) similar in cancer cases and controls. Those with biliary stones and no cancer tended to be younger than cancer cases. Gallbladder cancer was more common in women than men, while slightly more men had cancers of extrahepatic bile ducts and ampulla of Vater. Relative to controls, gallbladder cancer patients had a lower education level, were less likely to smoke or drink alcohol, more likely to have a history of diabetes, and had a higher BMI.

Table 2 shows ORs for biliary tract cancer in relation to gallstones. The overall prevalence of gallstones in the 959 controls was $23.4 \%$, with $5.9 \%$ reporting a history of cholecystectomy, $11.3 \%$ of gallstones, and $6.2 \%$ having silent gallstones detected through ultrasound. The $5.5 \%$ of controls with biliary sludge or cholesterol crystals detected on abdominal ultrasound were not classified as having gallstones. In contrast, a history of gallstones were found for $83.7,66.5$, and $53 \%$ of gallbladder, bile duct, and ampulla of Vater cancer, respectively. The ORs associated with stones were 23.8 (95\% CI, 17.0-33.4), 8.0 (95\% CI 5.6-11.4), and
4.2 (95\% CI 2.5-7.0) for cancers of the gallbladder, extrahepatic bile ducts, and ampulla of Vater, respectively. Further adjustment for smoking, drinking, BMI, tea drinking, aspirin use, and diabetes did not materially change the results. Location of gallstones was recorded for over $73 \%$ of the cancer patients with gallstones. For those with gallbladder cancer, $77 \%$ of the stones were in the gallbladder, $10 \%$ in the gallbladder neck, $9 \%$ in both the gallbladder and bile ducts, and $4 \%$ in bile ducts alone. The corresponding percentages for bile duct cancer were $68,7,11$, and $13 \%$, and for ampullary cancer $57,0,14$, and $28 \%$. The average age for biliary tract cancer cases with gallstones was about 5 years older than that for cases without gallstones (65 vs 60, $P=0.0005)$.

As shown in Table 3, overall, younger age at gallstone diagnosis or longer duration of stones alone did not modify the 23 -fold risk associated with gallstones. The very high ORs for bile duct and ampulla of Vater cancers related to having gallstones for 1 year or less were due to the frequency of incidental tumours shortly after or at the time of stone diagnosis. Similar risk patterns were observed for both men and women (data not shown).

Table 4 shows the combined effects of gallstones and related factors, including chronic cholecystitis, pancreatitis, diabetes, and high BMI, on biliary cancer risk. Since gallstones and cholecystitis may be detected concomitantly with biliary tract cancer, and gallstones may induce cholecystitis/pancreatitis, subjects with cholecystitis or pancreatitis diagnosed prior to 2 years of cancer diagnosis (mostly incidental tumours) or interview were excluded from the analysis. Subjects with both gallstones and (self-reported) chronic cholecystitis had a markedly increased risk of biliary

Table I Selected characteristics of cases and controls

\begin{tabular}{|c|c|c|c|c|c|c|c|}
\hline \multirow[b]{2}{*}{ Characteristics } & \multirow[b]{2}{*}{$\begin{array}{c}\text { Controls }^{\mathrm{a}} \\
n(\%)\end{array}$} & \multirow[b]{2}{*}{$\begin{array}{c}\text { Controls }^{\mathrm{b}} \\
n(\%)\end{array}$} & \multicolumn{3}{|c|}{ Biliary tract cancer $(n=267)$} & \multicolumn{2}{|c|}{ Biliary stones $(n=1037)$} \\
\hline & & & $\begin{array}{c}\text { Gallbladder cancer } \\
n(\%)\end{array}$ & $\begin{array}{c}\text { Bile duct cancer } \\
n(\%)\end{array}$ & $\begin{array}{c}\text { Ampulla of Vater cancer } \\
n(\%)\end{array}$ & $\begin{array}{c}\text { Gallbladder stones } \\
n(\%)\end{array}$ & $\begin{array}{c}\text { Bile duct stones } \\
n(\%)\end{array}$ \\
\hline oe (vears) & $959(100)$ & $902(100)$ & $368(100)$ & $191(100)$ & $68(100)$ & $774(100)$ & $263(100)$ \\
\hline $\begin{array}{l}\text { Age (years) } \\
\quad<55 \\
55-64 \\
\geqslant 65\end{array}$ & $\begin{array}{l}128(13.4) \\
269(28.1) \\
562(58.6)\end{array}$ & $\begin{array}{l}126(14.0) \\
259(28.7) \\
517(57.3)\end{array}$ & $\begin{array}{r}49(13.3) \\
96(26.1) \\
223(60.6)\end{array}$ & $\begin{array}{r}30(15.7) \\
47(24.6) \\
114(59.7)\end{array}$ & $\begin{array}{c}6(8.8) \\
20(29.4) \\
42(61.8)\end{array}$ & $\begin{array}{l}245(31.6)^{*} \\
218(28.2) \\
311(40.2)\end{array}$ & $\begin{array}{r}62(23.6) * \\
80(30.4) \\
|2|(46.0)\end{array}$ \\
\hline $\begin{array}{l}\text { Sex } \\
\quad \text { Male } \\
\text { Female }\end{array}$ & $\begin{array}{l}373(38.9) \\
586(61.1)\end{array}$ & $\begin{array}{l}357(39.6) \\
545(60.4)\end{array}$ & $\begin{array}{l}99(26.9)^{*} \\
269(73.1)\end{array}$ & $\begin{array}{l}99(51.8) \\
92(48.2)\end{array}$ & $\begin{array}{l}37(54.4) \\
31(45.6)\end{array}$ & $\begin{array}{l}263(34.0)^{*} \\
511(66.0)\end{array}$ & $\begin{array}{l}127(48.3) \\
136(51.7)\end{array}$ \\
\hline $\begin{array}{l}\text { Education } \\
\text { None/primary } \\
\text { Jr. middle } \\
\text { Sr. middle } \\
\text { Some college }\end{array}$ & $\begin{array}{l}396(41.3) \\
233(24.3) \\
190(19.8) \\
140(14.6)\end{array}$ & $\begin{array}{l}365(40.5) \\
221(24.5) \\
184(20.4) \\
132(14.6)\end{array}$ & $\begin{array}{l}198(53.8)^{*} \\
79(21.5) \\
50(13.6) \\
41(11.1)\end{array}$ & $\begin{array}{l}86(45.0) \\
43(22.5) \\
31(16.2) \\
30(15.7)\end{array}$ & $\begin{array}{r}29(42.7) \\
16(23.5) \\
15(22.1) \\
8(11.8)\end{array}$ & $\begin{array}{l}221(28.6) * \\
220(28.4) \\
194(25.1) \\
139(18.0)\end{array}$ & $\begin{array}{l}96(36.5) \\
67(25.5) \\
56(21.3) \\
44(16.7)\end{array}$ \\
\hline $\begin{array}{l}\text { Body mass index } \\
\quad<18.5 \\
\quad 18.5-22.9 \\
23.0-24.9 \\
\geqslant 25.0\end{array}$ & $\begin{array}{c}79(8.3) \\
404(42.2) \\
197(20.6) \\
278(29.0)\end{array}$ & $\begin{array}{c}78(8.7) \\
390(43.3) \\
184(20.4) \\
249(27.6)\end{array}$ & $\begin{array}{r}17(4.7) * \\
130(35.6) \\
73(20.0) \\
145(39.7)\end{array}$ & $\begin{array}{c}8(4.2) \\
86(45.5) \\
49(25.9) \\
46(24.3)\end{array}$ & $\begin{array}{c}1(1.5) \\
29(42.6) \\
15(22.1) \\
23(33.8)\end{array}$ & $\begin{array}{r}29(3.7) * \\
259(33.5) \\
197(25.5) \\
288(37.3)\end{array}$ & $\begin{array}{l}15(5.7) * \\
91(34.7) \\
62(23.7) \\
94(35.9)\end{array}$ \\
\hline
\end{tabular}

* $\chi^{2}$ test, $P<0.05$. Included all population controls. Bile duct cancer and ampulla of Vater cancer were compared with all population controls. ${ }^{b}$ Excluded population controls with a history of cholecystectomy $(n=55)$ or unknown history $(n=2)$. Gallbladder cancer cases were compared with this group. 
Table 2 Odds ratios ${ }^{a}$ and 95\% confidence intervals for biliary tract cancer in relation to gallstones, Shanghai, China

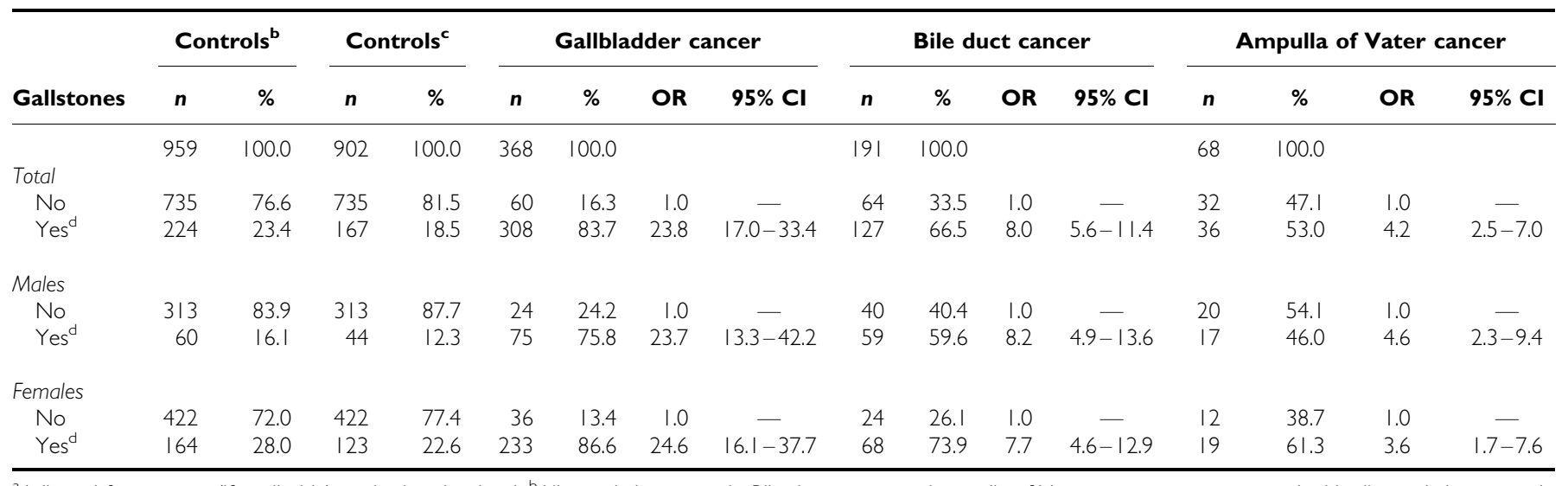

${ }^{a}$ Adjusted for age, sex (if applicable), and education level. ${ }^{b}$ All population controls. Bile duct cancer and ampulla of Vater cancer were compared with all population controls. ${ }^{\mathrm{c}}$ Excluded population controls with a history of cholecystectomy $(n=55)$ or unknown history $(N=2)$. Gallbladder cancer cases were compared with this group. ${ }^{\mathrm{d}}$ Included 59 silent gallstones.

Table 3 Odds ratios ${ }^{\mathrm{a}}$ and $95 \%$ confidence intervals for biliary tract cancer in relation to age at gallstone diagnosis and duration of stones, Shanghai, China

\begin{tabular}{|c|c|c|c|c|c|c|c|c|c|c|c|}
\hline & \multirow{2}{*}{$\begin{array}{c}\text { Controls } \\
n\end{array}$} & \multirow{2}{*}{$\begin{array}{c}\text { Controls }^{c} \\
n\end{array}$} & \multicolumn{3}{|c|}{ Gallbladder cancer } & \multicolumn{3}{|c|}{ Bile duct cancer } & \multicolumn{3}{|c|}{ Ampulla of Vater cancer } \\
\hline & & & $\mathbf{n}$ & OR & $95 \% \mathrm{Cl}$ & $n$ & OR & $95 \% \mathrm{Cl}$ & $\mathbf{n}$ & OR & $95 \% \mathrm{Cl}$ \\
\hline Total & 959 & 902 & 368 & & & 191 & & & 68 & & \\
\hline \multicolumn{12}{|c|}{ Duration of gallstones (years) } \\
\hline No gallstones & 735 & 735 & 60 & 1.0 & - & 64 & 1.0 & - & 32 & 1.0 & - \\
\hline$\leqslant 1$ & 74 & 70 & 138 & 24.5 & $16.4-36.5$ & 63 & 10.2 & $6.6-15.7$ & 20 & 6.5 & $3.5-12.1$ \\
\hline $2-4$ & 23 & 17 & 30 & 23.6 & $|2|-45.8$. & 7 & 3.7 & $|.5-9|$. & 2 & 1.7 & $0.4-7.7$ \\
\hline $5-9$ & 47 & 30 & 35 & 14.9 & $8.5-26.2$ & 11 & 2.9 & $1.4-5.9$ & 5 & 2.4 & $1.9-6.5$ \\
\hline$\geqslant 10$ & 80 & 50 & 90 & 23.3 & $15.0-36.3$ & 37 & 5.6 & $3.5-9.0$ & 4 & 1.1 & $1.4-3.2$ \\
\hline \multicolumn{12}{|c|}{ Age at diagnosis of gallstones } \\
\hline No gallstones & 735 & 735 & 60 & 1.0 & - & 63 & 1.0 & - & 32 & 1.0 & - \\
\hline$<45$ & 28 & 18 & 41 & 25.5 & $13.6-47.8$ & 16 & 6.2 & $3.2-12.2$ & 1 & 0.8 & $0.1-6.4$ \\
\hline $45-59$ & 82 & 53 & 82 & 19.2 & $12.4-29.7$ & 42 & 6.0 & $3.8-9.4$ & 9 & 2.6 & $1.2-5.6$ \\
\hline$\geqslant 60$ & 114 & 96 & 173 & 24.0 & $16.2-35.6$ & 62 & 7.2 & $4.7-11.1$ & 21 & 4.2 & $2.3-7.8$ \\
\hline \multicolumn{12}{|c|}{ Age at diagnosis of gallstones and duration of gallstones } \\
\hline No gallstones & 735 & 735 & 60 & 1.0 & - & 64 & 1.0 & - & 32 & 1.0 & \\
\hline$<55, \leqslant 1$ year & 8 & 7 & 12 & 16.1 & $5.7-45.3$ & 7 & 8.8 & $2.8-27.1$ & 2 & 8.3 & $1.4-49.1$ \\
\hline$<55,2-5$ years & 2 & 2 & 5 & 22.1 & $4.1-120.3$ & 2 & 9.3 & $1.3-68.7$ & I & 16.5 & $1.3-204.3$ \\
\hline$<55, \geqslant 6$ years & 60 & 38 & 79 & 25.6 & $16.0-38.8$ & 33 & 6.5 & $3.9-10.6$ & 4 & 1.7 & $0.6-5.1$ \\
\hline$\geqslant 55, \leqslant 1$ year & 66 & 63 & 126 & 25.4 & $16.7-38.8$ & 56 & 10.3 & $6.6-16.2$ & 18 & 6.8 & $3.5-12.9$ \\
\hline$\geqslant 55,2-5$ years & 34 & 26 & 34 & 17.7 & $9.7-32.2$ & 8 & 2.9 & $1.3-6.7$ & 2 & 1.5 & $0.3-6.8$ \\
\hline$\geqslant 55, \geqslant 6$ years & 54 & 31 & 37 & 16.8 & $9.4-30.0$ & 12 & 2.8 & $1.4-5.6$ & 4 & 1.7 & $0.6-5.2$ \\
\hline
\end{tabular}

${ }^{a}$ Adjusted for age, sex (if applicable), and education level. ' Included all population controls. Bile duct cancer and ampulla of Vater cancer were compared with all population controls. 'Excluded population controls with a history of cholecystectomy $(n=55)$ or unknown history $(N=2)$. Gallbladder cancer cases were compared with this group.

cancer, especially of the gallbladder $(\mathrm{OR}=34.3$; 95\% CI 19.9 59.2), although the interaction between gallstones and the cholecystitis was not statistically significant. Similarly, subjects with both gallstones and diabetes had a higher risk of gallbladder cancer $(\mathrm{OR}=30.7,95 \%$ CI $16.7-56.5)$. BMI and pancreatitis did not appear to modify the effect, and even among those with a low BMI $\left(<23 \mathrm{~kg} \mathrm{~m}^{-2}\right)$; gallstones were a significant risk factor for all three subsites.

Supplementary Information (see website) shows the morphological characteristics of gallstones for 249 biliary cancer patients (196 gallbladder, 53 bile duct) and 892 stone patients (668 gallbladder, 224 bile duct) as well as the biochemical composition of gallstones in 530 subjects with stones alone (358 gallbladder, 162 bile duct), 41 with gallbladder cancer, and 10 with bile duct cancer. Significant differences by subsite were seen in type, number, and weight, with pigment stones being more common in the bile duct patients or with bile duct cancer, and cholesterol stones in gallbladders patients or with gallbladder cancer. Compared with bile duct cancer, gallbladder cancer patients were more likely to have multiple ( 72 vs $58 \%, P=0.08$ ), larger, and heavier stones. Their stones were also heavier ( $4.9 v s 2.9 \mathrm{~g}, P=0.006)$ than those of gallstone patients, but no significant differences were seen in the size or number of stones. Patients with bile duct stones or extrahepatic bile duct cancer had higher levels of bile acids and bilirubin in their stones than patients with gallbladder stones or cancer $(P<0.001)$.

\section{DISCUSSION}

In this population-based case-control study in Shanghai, we confirmed that gallstones were a strong risk factor for all three subsites of biliary cancer. We estimated that $80 \%$ (95\% CI $0.75-$ $0.84), 59 \%(0.50-0.61)$, and $42 \%(0.29-0.57)$ of gallbladder, bile 
Biliary tract cancer

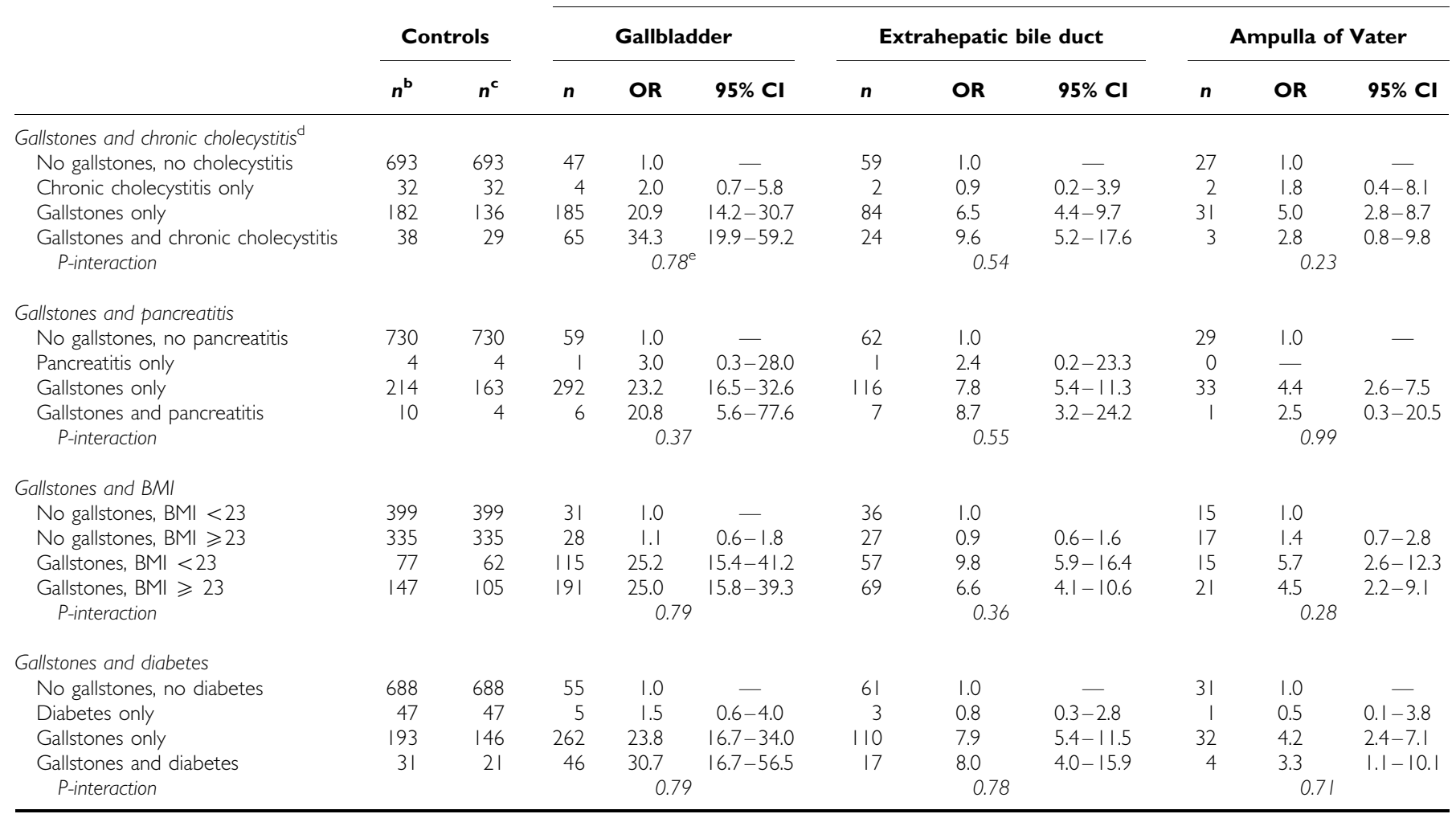

${ }^{a}$ Adjusted for age, sex, and education level. ${ }^{b}$ Included all population controls. Compared with cancer of the bile duct and ampulla of Vater. ${ }^{\mathrm{E}}$ Excluded population controls with a

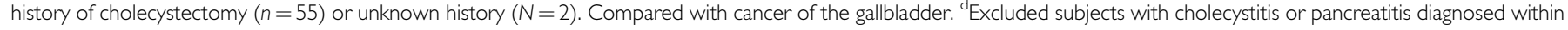
2 years of cancer diagnosis or interview.

duct, and ampulla of Vater cancers, respectively, in the Shanghai population were attributable to gallstones.

Although gallstones are a risk factor common to all three subsites of biliary cancer, differences in the magnitude of risks and in the prevalence and type of stones were notable. Molecular changes, including somatic mutations (such as K-ras and P16) and loss of heterozygosity, in these subsites have been described (Rashid et al, 2002; Ueki et al, 2004; Matsuba et al, 2005). Aetiologic heterogeneity is further supported by ethnic and geographic patterns between cancer subsites, with gallbladder cancer incidence especially high in native Americans and in Korea, India, and Eastern Europe, and the incidence of bile duct cancer highest in Japan (Hsing et al, 2006).

That cholesterol stones were commoner in gallbladder cancer while pigment stones predominated in bile duct cancer is consistent with the view that gallbladder cancer is more associated with lifestyle factors (diet, obesity, etc.), while bile duct cancer is associated with chronic infection or inflammation (Cetta, 1991). Cholesterol stones are associated with lithogenic bile supersaturated with cholesterol, due to increased hepatic secretion of cholesterol or diminished secretion of bile salts and phospholipids that maintain the solubility of cholesterol (el Zayadi et al, 1991). In contrast, pigment stones have a high biliary concentration and are closely linked to cirrhosis, chronic infection, and blood disorders (Swidsinski and Lee, 2001). Cholesterol stones are the commonest type in western population, while pigment stones predominate in developing regions of the world, especially in Asia. However, in China, during the past few decades, there has been an increase in cholesterol stones and a decrease in pigment stones, probably related to increasing obesity and a more westernised diet and lifestyle (Huang and Gu, 1987; Zhu et al, 1995; Wang et al, 2003).
In our study, the magnitude of the biliary cancer risks associated with gallstones was higher than in most previous studies (Lowenfels et al, 1985; Vitetta et al, 2000), possibly due to our more comprehensive assessment of gallstone status. Most previous studies were smaller (usually $<100$ ), not population-based, and lacked subsite-specific risks. A more pronounced association between gallstones and gallbladder cancer has been reported for women than men but in our study the effect of gallstone was similar in both genders.

The carcinogenic mechanisms in biliary cancer are poorly understood, but they may involve inflammatory changes near stones (Albores-Saavedra et al, 1980; Carriaga and Henson, 1995). This is supported by our 34 -fold risk associated with gallstones together with (self-reported) chronic cholecystitis, the possibly protective effects of aspirin use (Liu et al, 2005), and the association with a stone pro-inflammatory PTGS gene variant (Sakoda et al, 2006).

Despite their high risk, only about $1 \%$ of gallstone patients develop biliary cancer (Maringhini et al, 1987), indicating that other factors are involved. Except for cholecystitis, we did not detect interactions with other risk factors, perhaps because of small numbers. Further work is needed to clarify the role of infection as well as genetic and metabolic factors.

Several strengths of this study are notable. First, selection bias was minimal due to population-based design with high case ascertainment and participation. Second, nearly complete confirmation of case status minimised misclassification of cases. Third, the large sample size permitted the investigation of risk factors by anatomic subsite. Fourth, any misclassification of gallstones was minimal, since all cases had detailed clinical data, most controls underwent transabdominal ultrasound examination, 
and the validity of self-reports of gallstone history was high. Since only $6 \%$ of the population controls had silent gallstones, misclassification among the $13 \%$ of the controls who did not undergo ultrasound is minimal.

Despite the strong association between gallstones and biliary cancer, we could not establish a clear temporal relationship due to our cross-sectional design. However, in previous studies, age at gallstone diagnosis was usually 10-15 years younger than at cancer diagnosis, and risks were greatest among those with gallstones diagnosed at least 10 years earlier (Grimaldi et al, 1993). Despite this being the largest population-based study of biliary cancer to date, there was limited statistical power to evaluate the risk factors for ampulla of Vater cancer and the interactive effect of stones with other factors for all three subsites.

In summary, this population-based study in Shanghai confirmed that gallstones are an important risk factor for all three subsites of biliary cancer, particularly when complicated by chronic cholecystitis.

\section{ACKNOWLEDGEMENTS}

We thank Jiarong Cheng, Lu Sun, Kai Wu, Enju Liu, Xuehong Zhang, and the staff at the Shanghai Cancer Institute for data collection, specimen collection, and processing, surgeons at the collaborating hospitals for data collection, and local pathologists for pathology review; collaborating hospitals for data collection; and local pathologists for pathology review; Hope Webb-Cohen and Shelley Niwa of Westat for data preparation and management; and Janis Koci of the Scientific Applications International Corporation for management of the biological samples. This research was supported by the Intramural Research Program of the NIH, National Cancer Institute.

Supplementary information accompanies the paper on the British Journal of Cancer website (http://www.nature.com/bjc)

\section{REFERENCES}

Albores-Saavedra J, Alcantra-Vazquez A, Cruz-Ortiz H, Herrera-Goepfert R (1980) The precursor lesions of invasive gallbladder carcinoma. Hyperplasia, atypical hyperplasia and carcinoma in situ. Cancer 45: 919-927

Carriaga MT, Henson DE (1995) Liver, gallbladder, extrahepatic bile ducts, and pancreas. Cancer 75: $171-190$

Cetta F (1991) The role of bacteria in pigment gallstone disease. Ann Surg 213: $315-326$

Diehl AK (1983) Gallstone size and the risk of gallbladder cancer. JAMA 250: $2323-2326$

Diehl AK (1991) Epidemiology and natural history of gallstone disease. Gastroenterol Clin North Am 20: 1 - 19

Dutts Dutta U, Nagi B, Garg PK, Sinha SK, Singh K, Tandon RK (2005) Patients with gallstones develop gallbladder cancer at an earlier age. Eur $J$ Cancer Prev 14: 381 - 385

el Zayadi A, Ghoneim M, Kabil SM, el Tawil A, Sherif A, Selim O (1991) Bile duct carcinoma in Egypt: possible etiological factors. Hepatogastroentero$\log y$ 38: $337-340$

Fossati P, Ponti M, Prencipe L, Tarenghi G (1989) One-step protocol for assays of total and direct bilirubin with stable combined reagents. Clin Chem 35: $173-176$

Grimaldi CH, Nelson RG, Pettitt DJ, Sampliner RE, Bennett PH, Knowler WC (1993) Increased mortality with gallstone disease: results of a 20-year population-based survey in Pima Indians. Ann Intern Med 118: 185-190

Han TQ, Zhang SD, Tang WH, Jiang ZY (1998) Bile acids in serum and bile of patients with cholesterol gallstone. World J Gastroenterol 4: 82-84

Hsing AW, Gao YT, Devesa SS, Jin F, Fraumeni Jr JF (1998) Rising incidence of biliary tract cancers in Shanghai, China. Int J Cancer 75: $368-370$

Hsing AW, Rashid A, Devesa SS, Fraumeni Jr JF (2006) Biliary tract cancer. In: Schottenfeld D, Fraumeni Jr JF (eds) Cancer Epidemiology and Prevention 3rd edn, Oxford University Press, pp 787-800

Huang YQ, Gu C (1987) The changing pattern of cholelithiasis in Tianjin. Zhonghua Wai Ke Za Zhi 25: 346-381

Lazcano-Ponce EC, Miquel JF, Munoz N, Herrero R, Ferrecio C, Wistuba II, Alonso dR, Aristi UG, Nervi F (2001) Epidemiology and molecular pathology of gallbladder cancer. CA Cancer J Clin 51: 349-364

Liu E, Sakoda LC, Gao YT, Rashid A, Shen MC, Wang BS, Deng J, Han TQ, Zhang BH, Fraumeni Jr JF, Hsing AW (2005) Aspirin use and risk of biliary tract cancer: a population-based study in Shanghai, China. Cancer Epidemiol Biomarkers Prev 14: 1315-1318

Lowenfels AB, Lindstrom CG, Conway MJ, Hastings PR (1985) Gallstones and risk of gallbladder cancer. J Natl Cancer Inst 75: 77-80

Maringhini A, Moreau JA, Melton III LJ, Hench VS, Zinsmeister AR, DiMagno EP (1987) Gallstones, gallbladder cancer, and other gastrointestinal malignancies. An epidemiologic study in Rochester, Minnesota. Ann Intern Med 107: 30-35

Matsuba T, Qiu D, Kurosawa M, Lin Y, Inaba Y, Kikuchi S, Yagyu K, Motohashi Y, Tamakoshi A (2005) Overview of epidemiology of bile duct and gallbladder cancer focusing on the JACC Study. J Epidemiol 15 (Suppl 2): S150-S156

Oda A, Festi D, Sama C, Mazzella G, Alini R, Roda E, Barbara L (1975) Enzymatic determination of cholesterol in bile. Clin Chim Acta 64: $337-341$

Rashid A, Ueki T, Gao YT, Houlihan PS, Wallace C, Wang BS, Shen MC, Deng J, Hsing AW (2002) K-ras mutation, p53 overexpression, and microsatellite instability in biliary tract cancers: a population-based study in China. Clin Cancer Res 8: 3156-3163

Roda A, Festi D, Sama C, Mazzella G, Alini R, Roda E, Barbara L (1975) Enzymatic determination of cholesterol in bile. Clin Chim Acta 64: $337-341$

Rothman K, Greenland S (1998) Modern Epidemiology. Philadelphia: Lippincott-Raven

Sakoda LC, Gao YT, Chen BE, Chen J, Rosenberg PS, Rashid A, Deng J, Shen MC, Wang BS, Han TQ, Zhang BH, Cohen-Webb H, Yeager M, Welch R, Chanock S, Fraumeni Jr JF, Hsing AW (2006) Prostaglandinendoperoxide synthase 2 (PTGS2) gene polymorphisms and risk of biliary tract cancer and gallstones: a population-based study in Shanghai, China. Carcinogenesis 27: $1251-1256$

Swidsinski A, Lee SP (2001) The role of bacteria in gallstone pathogenesis. Front Biosci 6: E93-E103

Ueki T, Hsing AW, Gao YT, Wang BS, Shen MC, Cheng J, Deng J, Fraumeni Jr JF, Rashid A (2004) Alterations of p16 and prognosis in biliary tract cancers from a population-based study in China. Clin Cancer Res 10: $1717-1725$

Vitetta L, Sali A, Little P, Mrazek L (2000) Gallstones and gall bladder carcinoma. Aust NZ J Surg 70: 667-673

Wang GF, Stacey NH, Earl J (1990) Determination of individual bile acids in serum by high performance liquid chromatography. Biomed Chromatogr 4: $136-140$

Wang W, Wu ZS, Zhao D, Wu GX, Wang WH, Liu J, Zeng ZC, Qin LP, Liu J (2003) The trends of body mass index and overweight in population aged 25-64 in Beijing during 1984-1999. Zhonghua Liu Xing Bing Xue Za Zhi 24: $272-275$

Zatonski WA, Lowenfels AB, Boyle P, Maisonneuve P, Bueno de Mesquita HB, Ghadirian P, Jain M, Przewozniak K, Baghurst P, Moerman CJ, Simard A, Howe GR, McMichael AJ, Hsieh CC, Walker AM (1997) Epidemiologic aspects of gallbladder cancer: a case-control study of the SEARCH program of the International Agency for Research on Cancer. J Natl Cancer Inst 89: 1132-1138

Zhu X, Zhang S, Huang Z (1995) The trend of the gallstone disease in China over the past decade. Zhonghua Wai Ke Za Zhi 33: 652-658

Zou S, Zhang L (2000) Relative risk factors analysis of 3922 cases of gallbladder cancer. Zhonghua Wai Ke Za Zhi 38: 805-808 